\title{
(6) OPEN ACCESS \\ Pubic apophysitis: a previously undescribed clinical entity of groin pain in athletes
}

\author{
Matthieu Sailly, ${ }_{1}^{1}$ Rod Whiteley, ${ }^{2,3}$ John W Read, ${ }^{4}$ Bruno Giuffre, ${ }^{3,5}$ \\ Amanda Johnson, ${ }^{2,6}$ Per Hölmich ${ }^{7,8,9}$
}

${ }^{1}$ Centre Medical Synergie, Lausanne, Switzerland

${ }^{2}$ Aspetar Orthopaedic and Sports Medicine Hospital, Doha, Qatar

${ }^{3}$ University of Sydney, Sydney, New South Wales, Australia ${ }^{4}$ Castlereagh Imaging, St Leonards, Australia

${ }^{5}$ Radiology Department, Royal North Shore Hospital, Sydney, New South Wales, Australia ${ }^{6}$ University of Manchester, Manchester, UK

${ }^{7}$ Aspetar Sports Groin Pain

Center, Qatar Orthopaedic and Sports Medicine Hospital,

Doha, Qatar

${ }^{8}$ Arthroscopic Center Amager, Sports Orthopedic Research Center, Copenhagen, Denmark ${ }^{9}$ Copenhagen University Hospital, Amager-Hvidovre, Denmark

Correspondence to Dr Matthieu Sailly, Centre Medical Synergie, Rue du Grand Pré 2b, Lausanne CH-1007, Switzerland; matthieusailly@yahoo.fr

Accepted 10 April 2015

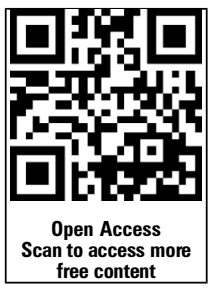

CrossMark

To cite: Sailly $M$,

Whiteley R, Read JW, et al.

Br J Sports Med

2015:49:828-834.

\section{ABSTRACT}

Background Sport-related pubalgia is often a

diagnostic challenge in elite athletes. While scientific attention has focused on adults, there is little data on adolescents. Cadaveric and imaging studies identify a secondary ossification centre located along the anteromedial corner of pubis beneath the insertions of symphysial joint capsule and adductor longus tendon. Little is known about this apophysis and its response to chronic stress.

Aim We report pubic apophysitis as a clinically relevant entity in adolescent athletes.

Methods The clinical and imaging findings in 26 highly trained adolescent football players (15.6 years \pm 1.3 ) who complained of adductor-related groin pain were reviewed. The imaging features (X-ray 26/26, US 9/26, MRI 11/26, CT 7/26) of the pubic apophyses in this symptomatic group were compared against those of a comparison group of 31 male patients (age range 9-30 years) with no known history of groin pain or pelvic trauma, who underwent pelvic CT scans for unrelated medical reasons.

Results All symptomatic subjects presented with similar history and physical findings. The CT scans of these patients demonstrated open pubic apophyses with stressrelated physeal changes (widening, asymmetry and small rounded cyst-like expansions) that were not observed in the comparison group. No comparison subject demonstrated apophyseal maturity before 21 years of age, and immaturity was seen up to the age of 26 years.

Conclusions This retrospective case series identifies pubic apophyseal stress (or 'apophysitis') as an important differential consideration in the adolescent athlete who presents with groin pain.

\section{INTRODUCTION}

Sport-related pubalgia in adult athletes remains a diagnostic and management challenge for the sports physician. Anatomically, we consider four potential sources of pain as most commonly incriminated: adductor longus, ilio-psoas, inguinal canal (associated or not with neural irritation and/or hernias), and pubic symphysis. Nevertheless, other causes for sport-related groin pain have also been cited (eg, hip pathology, rectus abdominis strain, pelvic stress fracture).

Unlike adults, the adolescent population is vulnerable to maturation-related injuries, such as osteochondral lesions, growth plate fractures, osteochondroses and apophysitis. ${ }^{1-4}$ Pubic symphysis maturation is a long and complex process. ${ }^{5}$ Developmentally, the pubic symphysis is the last part of the human skeleton to mature.
Developmental activity at the symphyseal joint face has been recorded as occurring until 35-40 years of age. ${ }^{6}$ Accordingly, this site is used to determine age at death of skeletal remains. ${ }^{6}$ Cadaveric studies ${ }^{7}$ describe the anatomy as including an apophysis (secondary ossification centre) as '... extended from the antero-medial pubis to lateral limit of the capsular tissues closely applied to fibrocartilaginous disk, capsular tissues and deeper sub-chondral bone'. During growth, the apophyseal cartilage undergoes endochondral ossification with irregular islands developing in ridges along the pubic subchondral surface. $\mathrm{MRI}^{78}$ shows that the pubic symphysis' appearance is age-dependant with all participants under 21 years demonstrating a pubic apophysis. Robinson $\mathrm{et}^{\mathrm{al}}$ concluded that "this junction of the pubis, apophysis and soft tissue might be expected to represent an area of biomechanical weakness that endures considerable forces during athletic single stance manoeuvres."

In young football players, injury to the pelvic or groin region represent between $4.9 \%$ and $11 \%$ of the injuries seen. ${ }^{9-12}$ Groin-related injuries tend to increase with maturation during adolescence. ${ }^{10} \mathrm{Le}$ Gall et $a l^{9}{ }^{9}$ in an elite youth football academy population, documented $20.4 \%$ prevalence of osteochondral disorders affecting the pelvis in the symptomatic subjects, specifically, they reported sites of injury as: the ischium, anterior inferior iliac spine, anterior superior iliac spine, iliac crest and lesser trochanter. The pubic symphysis was not cited. Oddly, pubic apophysitis is rarely mentioned as a differential diagnosis, ${ }^{13-15}$ and to the best of our knowledge this particular clinical entity has not been described previously.

Practically, the maturation process of the pubic apophysis bridges adolescence and adulthood, and therefore, most young football players signing a first professional contract should be considered as skeletally immature in this respect.

We aimed to report pubic apophysitis as a potential clinical entity in skeletally immature athletes and to propose a clinical and radiological workup.

\section{METHODS}

\section{Setting}

The Aspire Sports Academy's medical centre (Doha, Qatar) responsible for the care of approximately 180 boys aged $12-18$ years.

\section{Inclusion criteria}

Symptomatic group

During a 2-year period from September 2009 to September 2011, all athletes presenting with sport-related groin pain were examined by one 
sports physician with 8 years' experience in youth athletes. All injured athletes in this cohort were football players. A standardised examination and clinical workup were performed. We present this consecutive series of participants with a clinical working diagnosis of pubic apophysitis including the clinical and investigative findings of this group of male football players. For this cohort, ethics approval was obtained from the local authority.

\section{Comparison group}

We also characterised an asymptomatic comparison group. The comparison group comprised 31 males (9-30 years, mean: 21 years, $\mathrm{SD}=4.2$ ) who underwent a pelvic CT scan in two different radiology departments in France (François Mitterrand Hospital-Pau) and Australia (Royal North Shore Hospital-St Leonards). None was reporting of any sport-related groin pain at the time of the investigation. With ethics committee approval from both organisations, anonymous axial and coronal views were stored and analysed by two musculoskeletal radiologists, each with clinical experience of more than 20 years. Following previous work which described the maturation status of the tibial tubercle, ${ }^{16}$ a staging system was developed. For all participants, on both sides, presence of secondary ossification centres was recorded, and definitive apophyseal plate closure was noted. With this data, four developmental groups were then depicted; stage 1: open apophyseal plate without secondary ossification centre; stage 2: open apophyseal plate with secondary ossification centre; stage $3 \mathrm{a}$ : closed apophyseal plate without secondary ossification centre and finally, stage $3 \mathrm{~b}$ : closed apophyseal plate with remaining secondary ossification centre (figure 1). Finally, pelvic CT scans were compared with those from the symptomatic series.

\section{Exclusion criteria}

Symptomatic group

All participants presenting with a differential diagnosis of lumbar spine and/or hip joint pathology were excluded from this cohort. Given the skeletally immature population, a careful examination of the different apophyses surrounding the pelvis was performed. The anterosuperior and anteroinferior iliac spines, the lesser trochanter, and ischial apophyses were assessed for pathology or avulsion, and if present, these were eliminated from this group.

\section{Comparison group}

Participants referred for imaging for pain in the groin region were excluded from analysis.

\section{Chronological age}

The chronological age of the symptomatic and asymptomatic subjects was calculated from the date of birth obtained from the participants' medical records, referencing the date of radiological examination.

\section{Clinical examination}

The physical examination followed the protocol described by Holmich et al. ${ }^{17}$ The nine tests were performed on the adductor muscles, the iliopsoas, the symphysis joint and the abdominal muscles.

\section{Radiology}

During the clinical evaluation and workup, investigations were ordered and performed when clinically indicated. For this cohort, X-ray, ultrasound, CT and MRI were available for use on any athlete, and clinical indication was the only determinant of investigations performed.

All participants had standard anteroposterior (AP) radiographs of the whole pelvis in standing position as well as coned $\mathrm{AP}$ and lateral radiographs of the hip joint on the symptomatic side. Ultrasound of the hip joint, inguinal canal, symphysis pubis and adductor longus was performed in nine cases by the same sports physician who performed the clinical assessment, using a broadband $12-7 \mathrm{MHz}$ linear array transducer (Siemens Acuson 500, Erlangen, Germany) with both dynamic assessment of inguinal wall motion and Doppler assessment of soft tissue vascularity included. MRI was performed with a $1.5 \mathrm{~T}$ highfield imager (Siemens Magnetom Espree, Germany) in 11 cases. Although no single MRI examination protocol was consistently used in every case, all studies included a minimum of axial and coronal T1-weighted (echo time (TE) $14 \mathrm{~ms}$, repetition time (TR) $500 \mathrm{~ms}$, slice thickness $5 \mathrm{~mm}$ ) Fast Spin Echo (FSE) sequences and matching axial and coronal fat-suppressed sequences. The axial views in T2 and T1 fat-saturated sequences allowed an adequate depiction of the pubic apophysis. Fat suppression usually involved coronal PD-weighted (TE $28 \mathrm{~ms}$, TR $3700 \mathrm{~ms}$, inversion time $160 \mathrm{~ms}$, slice thickness $5 \mathrm{~mm}$ ) turbo inversion recovery magnitude and fat-saturated axial T2-weighted (TE $85 \mathrm{~ms}$, TR $4400 \mathrm{~ms}$, slice thickness $5 \mathrm{~mm}$ ) FSE sequences. CT was performed in seven cases using a 64-slice multidetector scanner (Siemens Somatom Sensation, bone reconstruction algorithm, exposure factors of $120 \mathrm{kV}$ and $160 \mathrm{~mA}$, pitch 0.9 , slice thickness $3 \mathrm{~mm}$ ). The pubic apophyses were then assessed from both the axial CT sections of primary acquisition and subsequent coronal reformations.

\section{RESULTS}

\section{History}

In this clinical series, players were aged between 13.3 and 18 years (mean age 15.6 years) (table 1 ). All athletes reported gradual or subacute onset of symptoms. Time from onset to medical consultation was a mean of 10 days (0-25 days). In the subacute cases $(n=9)$, pain usually started following repetitions of football shooting exercises (long crossover-type kicking) or forced hip abduction following a tackle. In the gradual onset cases $(n=17)$, athletes mentioned increase of training load especially during the preseason period or a change of ball size and weight during an age category upgrade. Symptoms were associated with shooting, passing, running and especially quick turning. All patients reported unilateral focal soreness localised to the region of the proximal adductor insertion.

\section{Physical examination}

Adduction against resistance was reported as painful with associated antalgic weakness in 20 of 26 participants, and was painful in all 26 participants when tested in end-range hip abduction. The palpation of the adductor longus muscle insertion elicited symptoms recorded on a visual analogue scale (mean reported pain $=70 / 100$ (range 30-90)). Passive stretching resulted in reported soreness at the pubic insertion after approximately $50^{\circ}$ hip abduction in all players. Other tests were all negative ${ }^{17}$ except for 5 of 26 participants who described soreness at the pubic symphysis during the hip evaluation with the FADDIR test (hip Flexion, Adduction and Internal Rotation).

\section{Radiology}

All 26 participants underwent X-ray investigation. No hip pathology was detected. All pubic symphyses had some non-specific 

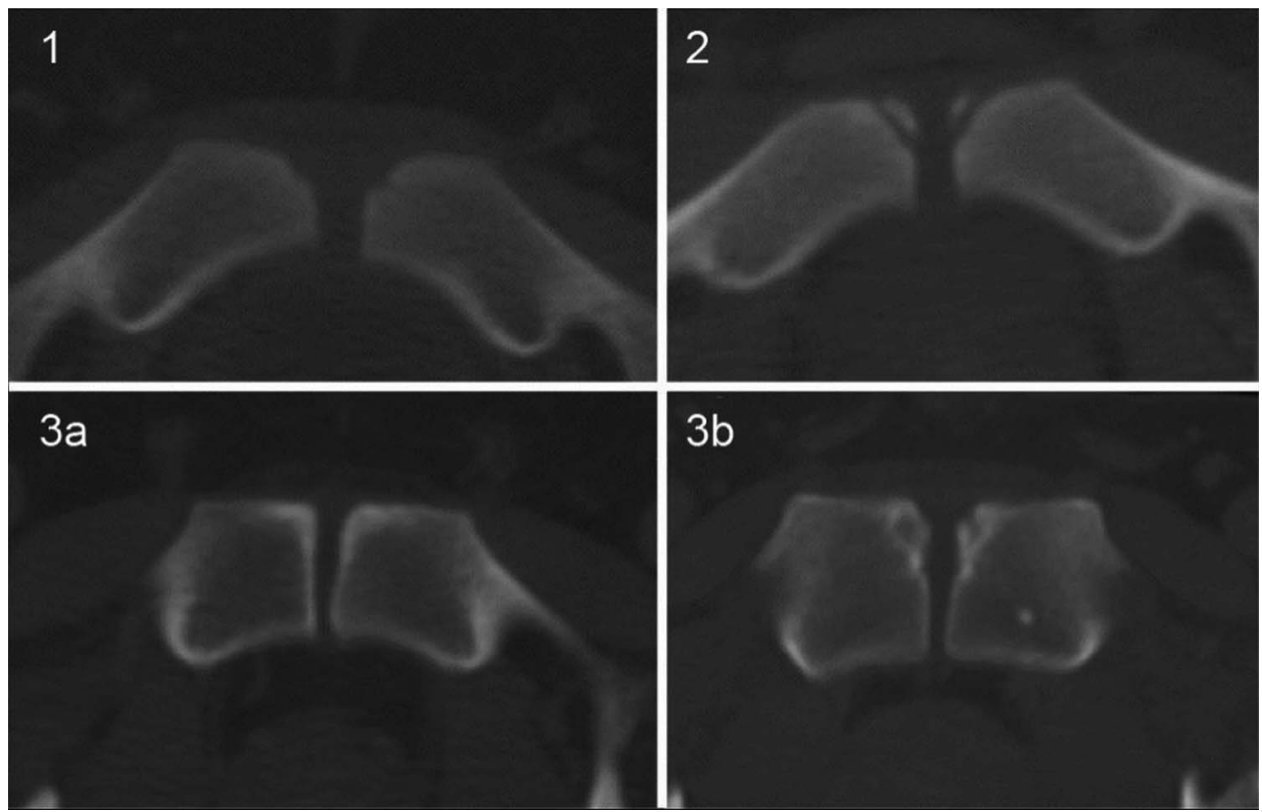

Figure 1 Axial CT scan depicting the clinical staging of maturation (stages 1, 2, 3a and 3b) from the comparison group. A secondary centre of ossification (stage 2) was deemed to be present only if a growth plate was definitely either partially or completely visible between the ossification centre and the metaphysis.

Table 1 Investigations performed and ages for each athlete in the clinical (painful) group

\begin{tabular}{|c|c|c|c|c|c|}
\hline Athlete & X-ray & Ultrasound & MRI & CT & Age at X-ray \\
\hline 1 & Yes & No & Yes & No & 14.9 \\
\hline 2 & Yes & Yes & No & No & 15.5 \\
\hline 3 & Yes & No & Yes & No & 16.7 \\
\hline 4 & Yes & Yes & No & No & 15.4 \\
\hline 5 & Yes & Yes & No & No & 16.1 \\
\hline 6 & Yes & Yes & No & No & 16.9 \\
\hline 7 & Yes & No & No & No & 16.5 \\
\hline 8 & Yes & Yes & Yes & Yes & 18.0 \\
\hline 9 & Yes & No & No & No & 16.2 \\
\hline 10 & Yes & Yes & Yes & Yes & 16.9 \\
\hline 11 & Yes & No & No & No & 16.3 \\
\hline 12 & Yes & Yes & No & No & 16.8 \\
\hline 13 & Yes & Yes & No & No & 16.1 \\
\hline 14 & Yes & Yes & No & No & 14.5 \\
\hline 15 & Yes & No & Yes & No & 14.4 \\
\hline 16 & Yes & No & No & No & 16.8 \\
\hline 17 & Yes & No & Yes & No & 13.8 \\
\hline 18 & Yes & No & Yes & No & 13.9 \\
\hline 19 & Yes & No & Yes & No & 13.3 \\
\hline 20 & Yes & No & No & Yes & 13.6 \\
\hline 21 & Yes & No & Yes & No & 15.3 \\
\hline 22 & Yes & No & Yes & No & 14.6 \\
\hline 23 & Yes & No & Yes & Yes & 17.0 \\
\hline 24 & Yes & No & No & Yes & 14.0 \\
\hline 25 & Yes & No & No & Yes & 17.5 \\
\hline 26 & Yes & No & No & Yes & 15.0 \\
\hline Totals & 26 & 9 & 11 & 7 & \\
\hline & & & \multicolumn{2}{|c|}{ Average } & 15.61 \\
\hline & & & \multicolumn{2}{|l|}{ S.D } & 1.32 \\
\hline & & & \multicolumn{2}{|c|}{ Minimum } & 13.3 \\
\hline & & & \multicolumn{2}{|c|}{ Maximum } & 18.0 \\
\hline
\end{tabular}

signs reported as: 'pubic erosion, symphyseal irregularity, anteroinferior corner erosion' (figure 2).

Ultrasound assessments, when performed (9 of 26), were negative for any proximal myo-tendinous strain of the adductor longus. No hip joint effusion was found. Careful assessment of the symphyseal cortex showed irregularity or cortical interruption (figure 3) associated with mild Doppler activity of the proximal adductor tendon and hypoechoic regions within the tendon.

MRI, when performed (11 of 26), displayed pubic symphysis changes reported as 'erosions', 'subchondral sclerosis', 'cystic changes' and 'bilateral symphyseal bony oedema' without any adductor tendon avulsion. In fluid-sensitive sequences, moderate hypersignal within the enthesis was noted. No muscle strain was found around the hip joint, nor was any signal abnormality reported within the hip joint (figure 4).

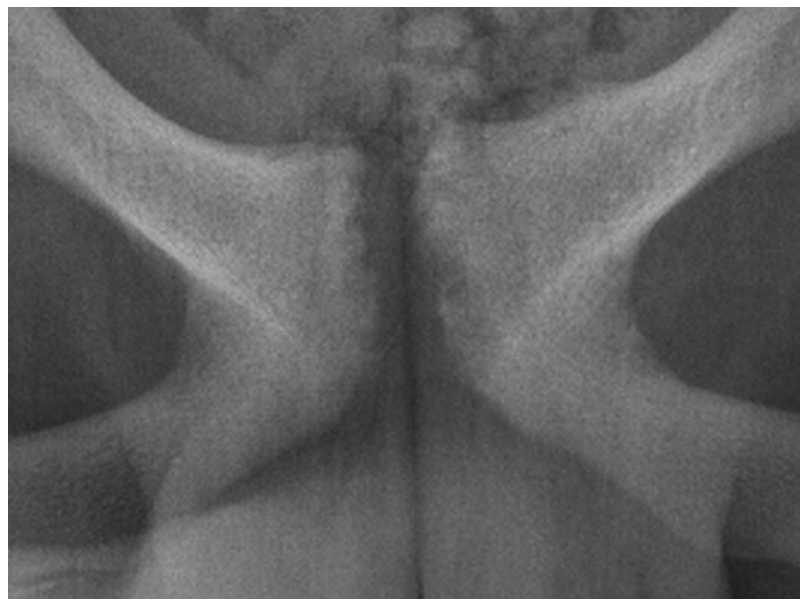

Figure 2 Anteroposterior pelvic X-ray showing pubic symphysis stress-related signs. 
Figure 3 Ultrasound appearance of a stage 2 subject (longitudinal section, upper). Note the cortical irregularity at the anterior and inferior aspect of the pubic symphysis. superior is left in the image, anterior is
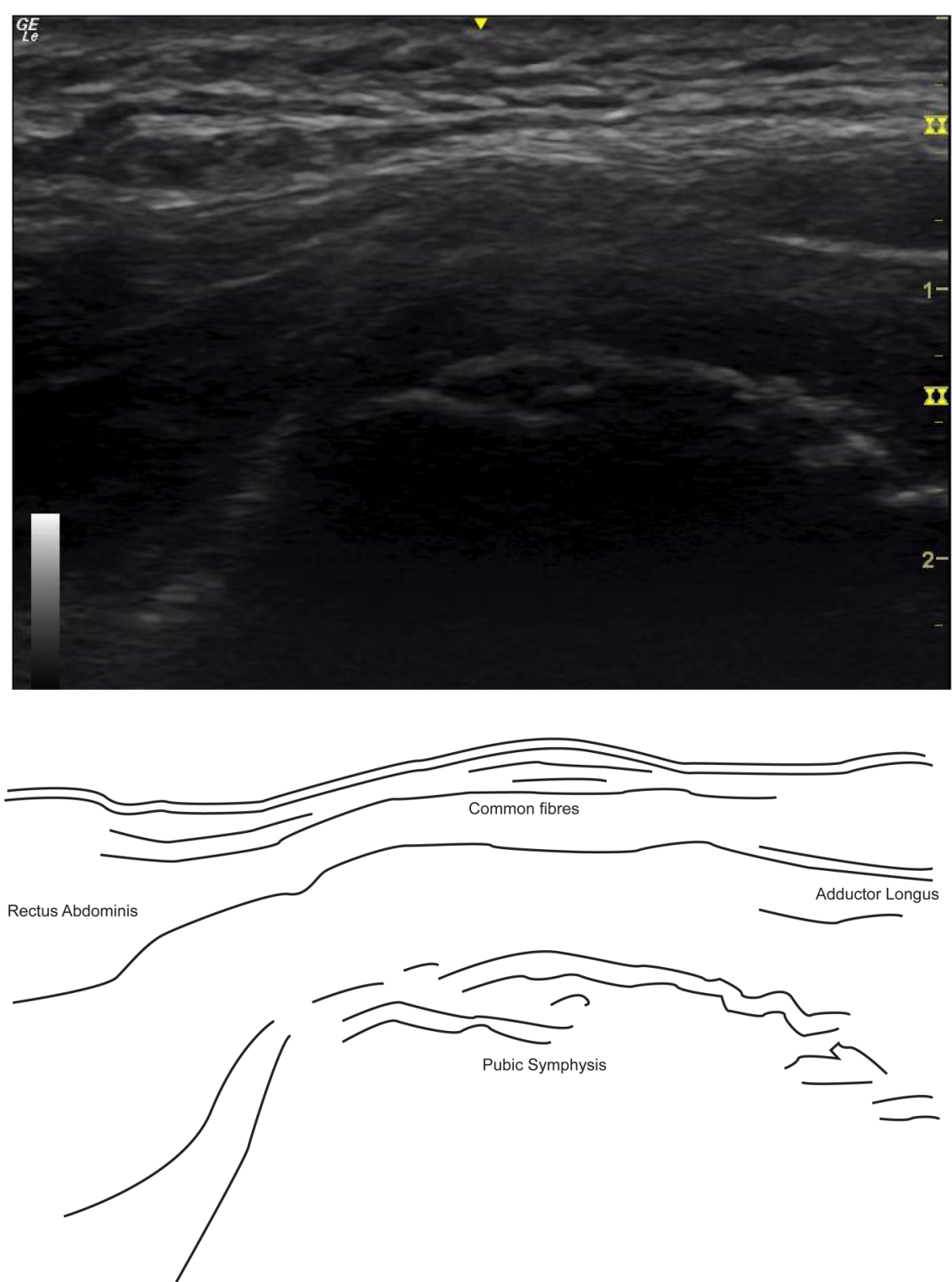

For seven cases (of 26), CT scan was requested. All showed a non-fusion of the secondary ossification centre of the pubic symphysis in axial (figure 5) and coronal views. The apophyseal plate exhibited some stress-related signs unilaterally on the painful side in 7 of 7 cases; and widening, asymmetrical irregularities and cyst-like lucency in 2 of 7 cases (figure 6).

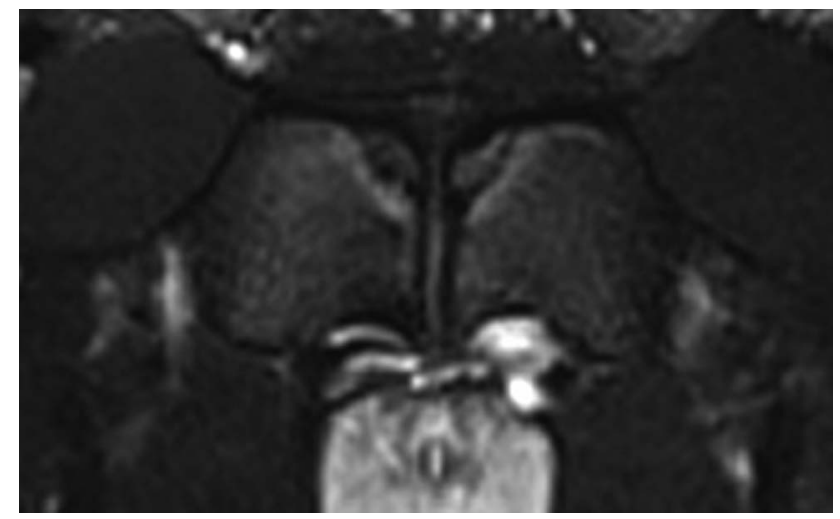

Figure 4 T1 fat-saturation MRI showing depiction of the pubic symphysis and adjacent apophysis.

\section{Comparison group} demonstration of a physis and the ossicle as described above. Analysis of the CT scans of the asymptomatic subjects resulted in 3 participants (9-16 years) included in stage $1 ; 13$ participants $(16-26$ years) in stage $2 ; 13$ participants in stage

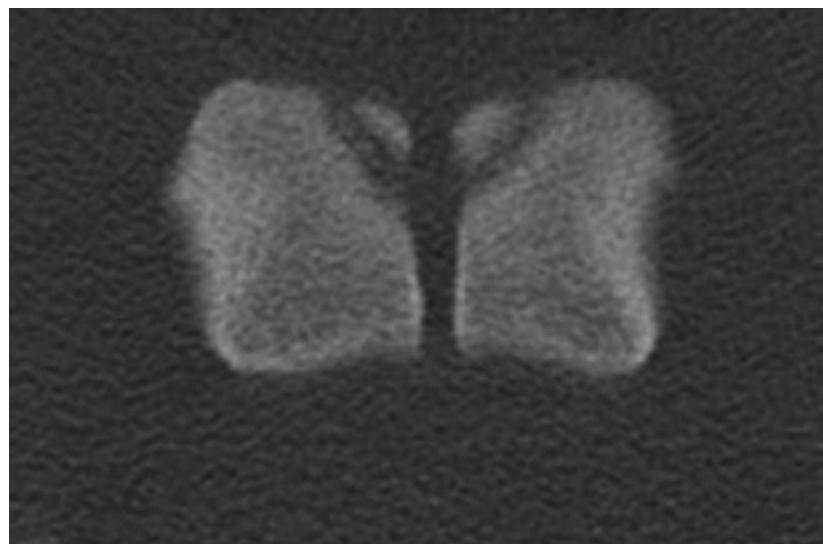

Figure 5 Axial CT scan depicting pubic apophysis.
Maturation status of the pubis was classified according to the 

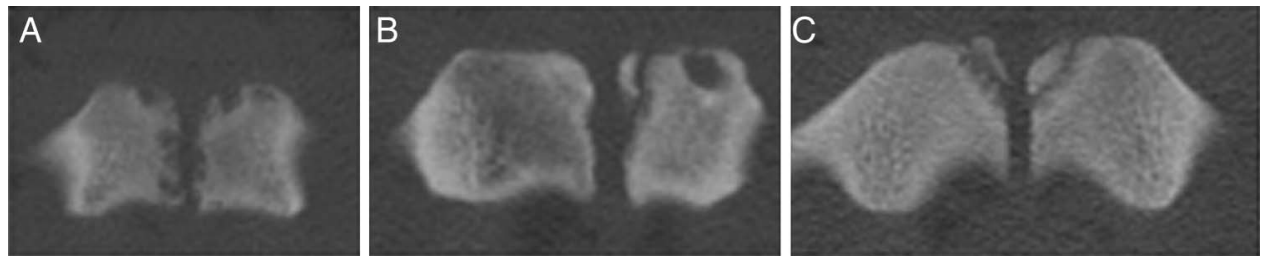

Figure 6 CT scans from three of the participants within the symptomatic group demonstrating stress-related changes at the pubis. (A) Cystic changes; (B) asymmetrical irregularities and cystic changes and (C) unilateral widening of the pubic apophysis.

3a (21-27 years) and 2 participants $(25-30$ years) in stage $3 \mathrm{~b}$ (figure 7 ).

All participants in the comparison series showing complete closure of the apophyseal plate were older than 21 years. Four cases $(13 \%)$ older than this had an incomplete maturation of the pubic apophysitis where the apophyseal plate was not completely closed.

The symptomatic group was aged $13.3-18.0$ years. Of the six asymptomatic comparison, participants in this same age category (13-18 years) 2 of $6(33 \%)$ were found to have an open apophyseal plate, and 4 of $6(67 \%)$ had a secondary ossification centre.

Pelvis CT scans from the asymptomatic group were finally compared with the seven cases from the clinical series that had CT performed. No stress-related signs, such as widening, subchondral cysts, or asymmetries were noticed at the apophyseal plate of the comparison group, whereas the clinical series depicted these changes.

\section{Clinical management}

Management principles were essentially antalgic. All injured players underwent conservative treatment with complete rest from aggravating activities. They all went back to their previous sporting levels without any recurrence at follow-up to a minimum of 6 months. Time to full return to play was between 6 weeks and 4 months. No analgesic medication was given, nor were there local injections of any infiltrates. All the injured football players performed daily rehabilitation under the supervision of a sports physiotherapist. The rehabilitation plan was divided into three stages: stage 1 , obtain complete analgesia with local physical modality treatment and then start progressive adductor stretching. Stage 2 worked to correct postural control impairment from initial static positions working towards complex dynamic exercise focusing on pelvic and trunk control. Finally, in stage 3, progressive football-specific exercises were conducted in a graduated manner until the player could perform all duties required in a normal training or playing session. Patients were moved forward (or back) through these stages according to their reports of pain during and subsequent to the sessions.

\section{DISCUSSION}

This case series documents a previously under-recognised clinical entity: apophyseal injury of the pubic symphysis. We believe that the combination of the late maturation of this apophysis (21 years or older), and the high training loads of these boys likely contributed to the clinical picture.

\section{Symphyseal maturational anatomy}

Meindl et $a l^{6}$ showed that the maturation of the pubic symphysis is a complex process which depends on: age, gender, race and environmental factors. In the clinical group presented here, these athletes were submitted to heavy training loads in an early football specialisation strategy, and we speculate that the loading likely influences the maturation of the pubic apophysis.

The analysis of the asymptomatic comparison group confirmed the previous findings in the literature, all participants with a fully mature pubic apophysis were older than 21 years. This reinforces our hypothesis that the maturation of the pubic apophysis bridges adolescence and adulthood, and may represent the start of the endochondral ossification of the secondary
Figure 7 Distribution of the maturation status (stages 1-4) of the 31 asymptomatic comparison subjects (as determined by CT examination) according to chronological age (years).

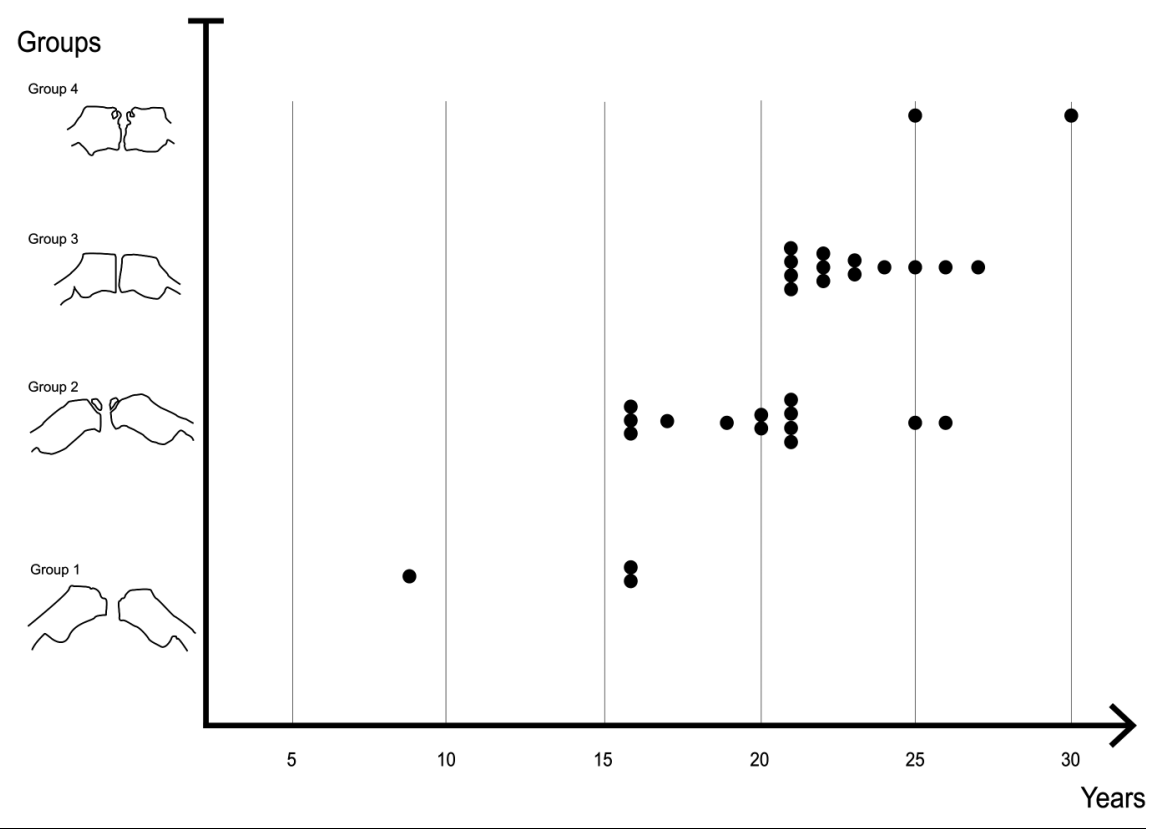


ossification centre. The limit between stages 2 and $3 \mathrm{a}$ seems to be around 21 years of age, which represents the complete closure of the pubic apophyseal plate. Less commonly, in this series, 4 of 21 asymptomatic subjects older than 21 years exhibit incomplete closure of the apophyseal plate which may be a sign of delayed maturation of the apophysis. Typically, between 16 and 21 years of age, the pubic apophysis matures (in males) and athletes may be at risk of pubic apophysitis during these years.

In this case series, there were no football players over 18 years of age as they had then left the academy to join professional clubs where epidemiological data were not available. Anecdotally, we note a number of cases of symptomatic chronic apophysitis in players older than 25 years with incomplete fusion of the pubic apophysitis.

\section{Diagnostic strategy}

As with other apophysitis, pubic apophysitis remains a clinical diagnosis supported by radiological investigations. This clinical entity must be suspected when skeletally immature athletes (in this data, males at least up to 21 years of age), who are reporting adductor-related groin pain. Symptom onset is typically gradual. Clinically, pain is reproduced through palpation of the adductor longus insertion on the pubis. Some hip testing appeared to be positive despite the absence of demonstrable joint pathology. The FADDIR test is reported to display poor specificity, ${ }^{18}$ and the pain reproduced by this testing might be explained by the compression force applied on this region during the adduction and internal rotation of the hip. In this study, X-rays, ultrasound and MRI were used to rule out differential or additional diagnosis. In the opinion of the authors, CT scan allowed the best depiction of the pubic apophysis both on axial and coronal view, while T1 fat-saturation MRI (1.5 T) sequence was not as helpful. Unfortunately, due to radiation on the gonadal region of these adolescent boys, the use of CT scan was restricted, and only performed in cases where other investigations were inconclusive. Although such imaging is not routinely available, our recent experience with $3 \mathrm{~T}$ MRI appears promising.

\section{Pathomechanics}

Previous studies on apophysitis questioned the role of tensile forces in their causality. ${ }^{19}{ }^{20}$ In pubic apophysitis, the close anatomical relationship between the apophysis and the common fibres from the rectus abdominis and the adductor longus tendons may be the source of local compression forces. We suggest that pathogenesis may be related to the combination of traction and compressive forces. The proximity of the symphysis joint and its capsule may add some shearing forces that may impact the apophyseal maturation.

\section{Clinical implications}

Practically, adolescent football players who are under heavy training load following an early specialisation model may be at risk of developing this apophysitis. Football academies should pay attention to prodromal adductor-related symptoms in this population in order to allow physiological maturation of the pubic apophysis and avoid chronic symptoms. Training load and strict monitoring of adductor symptoms should be conducted in order to minimise this risk. The full maturation of the pubic symphysis may become an indirect sign of readiness to cope with adult training load. Skeletally immature athletes should remain in an at-risk group until complete maturation of the pubic apophysis.
In this case series, all patients were managed conservatively without any early recurrence. We suggest that mechanical loads need to be greatly decreased on the proximal adductor tendon to allow a correct maturation of the ossification centre. This clinical entity responds well to initial rest, then progressive and careful rehabilitation guided by pain response. This may decrease the risk of future complications such as fusion delay or later non-union. This contrasts with the more commonly encountered (skeletally mature) entity of adductor-related groin pain $^{20}$ which is shown to respond to an immediate loading programme. ${ }^{21}$ In our experience, some degree of pain can be tolerated in the management of skeletally mature, adductor-related groin pain while we suggest that in this group (pubic apophysitis) a completely antalgic management strategy should be employed. We suggest that in cases of presumed adductorrelated groin pain, where athletes report increased symptoms after starting a loading programme, the exclusion of pubic apophysitis as a differential diagnosis is an important step lest the athlete be inappropriately subjected to injections (eg, corticosteroids) or surgical release of the adductors. ${ }^{18} 23$

Sequelae of apophysitis are often described in Osgood-Schlatter and Sinding Larsen diseases, as resulting in chronic symptoms with insertional tendinopathy. The same long-term evolution may be proposed in pubic apophysitis. Incomplete apophyseal fusion may be seen in participants who keep playing despite apophyseal stress, and develop chronic symptoms.

\section{Limitations}

This clinical series was intended to highlight a new observation as regards groin pathoanatomy. As a result, it has a number of limitations. The physical examination was standardised but the imaging performed was according to the clinical reasoning, bias and local imaging resources of the individual sports medicine physician. This did result in some variance in the imaging used in each case. In future analyses, imaging of each modality will be performed in a larger cohort to document the differences in imaging appearance in symptomatic and asymptomatic subjects. Similarly, follow-up imaging examination could be performed to ascertain the natural course of identified abnormalities and their association with symptoms.

\section{Summary}

This case series documents the clinical entity of pubic apophysitis in male football players over the age of 14 years. The asymptomatic comparison group confirmed that while physeal irregularity is common in the symptomatic cohort, it is uncommon in asymptomatic subjects, and that apophyseal maturation starts around 16 years of age, continuing until approximately 21 years of age. We suggest that in early adulthood, repeated stress on the proximal adductor insertion may lead to impairment of the pubic apophysis associated with chronic symptoms.

\section{What are the new findings?}

- The maturation of this apophysis starts at 16 years of age and continues up to approximately 21 years in male participants; accordingly, it bridges adolescence and adulthood.

- Pubic apophysitis may explain some adductor-related groin pain in adolescent athletes. 
How might it impact on clinical practice in the near future?

- The diagnosis of pubic apophysitis needs to be considered in adolescent athletes reporting adductor-related groin pain. An athlete in his early 20 s should be considered as skeletally immature.

- Signs of apophyseal plate stress may be assessed with CT scan, however, the risk of exposure to ionising radiation in this age group makes this ill-advised. More modern MRI examinations appear a promising alternative.

- Conservative treatment should be the first line of management to allow physeal maturation.

Contributors MS was involved in the original study design, data collection, data analysis and manuscript preparation. RW and PH were involved in study design and manuscript preparation. BG and JWR were involved in the radiological data collection and analysis of the asymptomatic comparison group. AJ was involved in the data analysis. All authors have reviewed and approved the final submission.

Competing interests None declared.

Patient consent Obtained.

Ethics approval Ethics Board of the Anti-Doping lab, Qatar, Ethical approval number: E20140000012.

Provenance and peer review Not commissioned; externally peer reviewed.

Open Access This is an Open Access article distributed in accordance with the Creative Commons Attribution Non Commercial (CC BY-NC 4.0) license, which permits others to distribute, remix, adapt, build upon this work non-commercially, and license their derivative works on different terms, provided the original work is properly cited and the use is non-commercial. See: http://creativecommons.org/ licenses/by-nc/4.0/

\section{REFERENCES}

1 Carr KE. Musculoskeletal injuries in young athletes. Clin Fam Pract 2003; 5:385-415.

2 Hogan KA, Gross RH. Overuse injuries in pediatric athletes. Orthop Clin North Am 2003;34:405-15.

3 McKinney BI, Nelson C, Carrion W. Apophyseal avulsion fractures of the hip and pelvis. Orthopedics 2009;32:42.

4 Morelli V, Weaver V. Groin injuries and groin pain in athletes: part 1. Primary Care 2005;32:163-83.
5 Scheuer L, Black S. Development and ageing of the juvenile skeleton. In: Margaret Cox \& Simon Mays, eds. Human osteology in archaeology and forensic science 2000:9-22.

6 Meindl RS, Lovejoy CO, Mensforth RP, et al. A revised method of age determination using the os pubis, with a review and tests of accuracy of other current methods of pubic symphyseal aging. Am J Phys Anthropol 1985;68:29-45.

7 Robinson P, Salehi F, Grainger A, et al. Cadaveric and MRI study of the musculotendinous contributions to the capsule of the symphysis pubis. AJR Am J Roentgenol 2007;188:W440-5.

8 Robinson P, Barron DA, Parsons W, et al. Adductor-related groin pain in athletes: correlation of MR imaging with clinical findings. Skeletal Radiol 2004;33:451-7.

9 Le Gall F, Carling C, Reilly T, et al. Incidence of injuries in elite French youth soccer players: a 10-season study. Am JSports Med 2006;34:928-38.

10 Froholdt $A$, Olsen $\mathrm{OE}$, Bahr R. Low risk of injuries among children playing organized soccer: a prospective cohort study. Am J Sports Med 2009;37:1155-60.

11 Wong P, Hong Y. Soccer injury in the lower extremities. Br J Sports Med 2005;39:473-82.

12 Price RJ, Hawkins RD, Hulse MA, et al. The Football Association medical research programme: an audit of injuries in academy youth football. $\mathrm{Br}$ J Sports Med 2004;38:466-71.

13 Orchard J, Read JW, Verrall G, et al. Pathophysiology of chronic groin pain in the athlete. Int J Sports Med 2000;1:1-16.

14 Orchard JW, Read JW, Neophyton J, et al. Groin pain associated with ultrasound finding of inguinal canal posterior wall deficiency in Australian Rules footballers. Br J Sports Med 1998;32:134-9.

15 Bouvard M, Lippa A, Reboul G, et al. La pubalgie du sportif. J Traumatol Sport 2012;29:105-28

16 Sailly M, Whiteley R, Johnson A. Doppler ultrasound and tibial tuberosity maturation status predicts pain in adolescent male athletes with Osgood-Schlatter's disease: a case series with comparison group and clinical interpretation. Bri J Sports Med 2013;47:93-7.

17 Holmich $\mathrm{P}$, Holmich LR, Bjerg AM. Clinical examination of athletes with groin pain: an intraobserver and interobserver reliability study. $\mathrm{Br} J$ Sports Med 2004;38:446-51.

18 Akermark $C$, Johansson C. Tenotomy of the adductor longus tendon in the treatment of chronic groin pain in athletes. Am J Sports Med 1992;20:640-3.

19 Weir A, de Vos RJ, Moen M, et al. Prevalence of radiological signs of femoroacetabular impingement in patients presenting with long-standing adductor-related groin pain. Br J Sports Med 2011;45:6-9.

20 Ducher G, Cook J, Lammers G, et al. The ultrasound appearance of the patellar tendon attachment to the tibia in young athletes is conditional on gender and pubertal stage. J Sci Med Sport 2010;13:20-3.

21 Holmich P. Long-standing groin pain in sportspeople falls into three primary patterns, a "clinical entity" approach: a prospective study of 207 patients. $\mathrm{Br} J$ Sports Med 2007;41:247-52; discussion 52.

22 Holmich $\mathrm{P}$, Uhrskou P, Ulnits $\mathrm{L}$, et al. Effectiveness of active physical training as treatment for long-standing adductor-related groin pain in athletes: randomised trial. Lancet 1999;353:439-43.

23 Orchard JW, Cook JL, Halpin N. Stress-shielding as a cause of insertional tendinopathy: the operative technique of limited adductor tenotomy supports this theory. J Sci Med Sport 2004;7:424-8. 